\title{
Coomonte, hoy
}

\author{
María Teresa González Vicario
}

La trayectoria artística de un escultor está sometida a unas continuas transformaciones en las que se advierte el deseo de investigar en el atractivo, aunque no siempre fácil, mundo de las formas, y de experimentar con los nuevos materiales, sin abandonar por ello los considerados como tradicionales. Todo este difícil proceso cristaliza en una serie de obras que son claros exponentes de su evolución artística, de sus preocupaciones, pero también de su esperanza.

José Luis Alonso Coomonte (Benavente, Zamora, 1932), hombre de profundas raices castellanas, vive y siente la problemática de Castilla, de esa tierra con la que cada día se encuentra más identificado. Al comenzar la década de los años ochenta decidió abandonar Madrid para fijar su residencia en Zamora y, desde alli, continuar su actividad artística ${ }^{1}$.

1 Sobre la etapa artística de Coomonte anterior a su llegada a Zamora véase:

J. Boneu FarRe, Coomonte, Madrid (s. n.), Imp. Reproducciones Offset Bárcena, 1975.

COOMONTE. Exposición celebrada en las salas de exposiciones de la Dirección General del Patrimonio Artístico y Cultural. Madrid, octubre - noviembre 1975 (textos de Manuel Conde y José María Ballester).

COOMONTE. Exposición celebrada en la Sala de Cultura de la Caja de Ahorros de Navarra. Pamplona, febrero, 1979 (textos de Manuel Conde y Sebastián López).

J. A. Gaya Nuño, El hierro en el arte español. Formas de la escultura contemporánea, Madrid, E. Aguado, 1966, pág. 17 y 219.

F. DE INZA, "José Luis Alonso Coomonte", Gremio 62. Catálogo de la Sala de Exposiciones de la Dirección General de Bellas Artes, núm. LXI, Madrid, Dirección General de Bellas Artes, diciembre 1963, fol. 8 y 9.

J. MARIN-MEDINA, La escultura española contemporánea (1800-1978). Historia y evaluación critica, Madrid, Edarcón, 1978, pág. 315 y 316.

F. Portela, "Escultura", Historia del Arte Hispánico. El siglo xx, por C. Sambricio, F. Portela, F. Torralba, vol. VI, Madrid, Alhambra, 1980, pág. 192, 193 y 214.

J. A. Ramirez, "Los niveles funcionales en la obra de arte: El caso de José Luis Coomonte", Temas de arquitectura y urbanismo, 1979, núm. 226, pág. 37-47. 
El diario contacto con la sequedad y aspereza del paisaje castellano, el conocimiento de la realidad de sus gentes, las propias vivencias, todo ello va calando muy hondo en su personalidad para, al mismo tiempo, proyectarse en su obra, en la que se advierten dos constantes, dos fuentes de inspiración y de continuo aprendizaje: la naturaleza y la historia.

Una de las aportaciones de Coomonte al campo de la escultura está basada en la estrecha relación con la arquitectura. Entre los años 1984 y 1985 trabajó, en colaboración con el arquitecto Ramón Cañas, en el Banco de España (fig. 1), de Zamora. La obra resultante de dicha colaboración es un edificio estructuralmente basado en la verticalidad y horizontalidad de unos volúmenes de granito rosa apomazado, sobre cuya superficie se proyectan, a distintos niveles, unas celosias de aluminio.

En la realización de estas celosías (fig. 2), según Coomonte en forma de cesta porque avanzan sobre el plano de la pared $1,50 \mathrm{~m}$, se han empleado 45.000 kilos de aluminio fundido que cubren una superficie de $1.600 \mathrm{~m}^{2}$. Dadas las dimensiones de esta obra, se optó por una sofisticada técnica a través de un rápido proceso de ejecución, muy en consonancia con los avances de la tecnología del momento. Se partió de un módulo $(0,75 \times 0,75 \mathrm{~m})$ fundido en una coquilla (fig. 3), que, desprovista de ciertos elementos, guarda en la actualidad el Banco de España. Dicho módulo se repite como una constante a lo largo y a lo ancho de cada celosía, originando un compacto conjunto en el que los motivos decorativos que lo componen se destacan con precisión y claridad sobre el fondo de granito rosa. El punto de partida de esta obra, según su autor, se encuentra en la sencillez de una reja (fig. 4) de la románica iglesia de San Cipriano, en Zamora, obra de principios del siglo XII, que ha sufrido con posterioridad diversas transformaciones. En dicha reja, la verticalidad de un elemento, atravesado por otros dos en sentido horizontal, fue configurando en el escultor la creación de un módulo cuadrangular, cortado por dos vástagos que aprisionan líneas ondulantes hasta conformar unos rizos dispuestos verticalmente, contrapuestos a otros que giran en sentido contrario para romper, en cierto modo, la simetría del conjunto, un conjunto pleno de solidez y de una plástica sobriedad, en el que se busca con insistencia la repetición de unas formas, que permiten el paso de la luz entre ellas para proyectar, paralelamente, sombras que ocasionan contrastes lumínicos. En esta obra se encuentra, por lo tanto, la pervivencia de una idea basada en un pasado artístico que ha sido traducida a un lenguaje muy actual dentro de la estética contemporánea.

El acceso a la puerta principal del edificio está flanqueado por una original balaustrada de hierro forjado (fig. 5), compuesta por orgánicas 
formas inspiradas en el mundo vegetal y constituidas por unos elementos verticales de diferente longitud, rematados en una esfera.

Las puertas son de aluminio (fig. 6), fundidas a la arena, y en sus superficies se advierte el recuerdo de los abiertos campos castellanos, plagados de surcos, en este caso unos irregularas surcos que albergan formas esféricas, a modo de semillas (fig. 7), evocándose una vez más la naturaleza, una de las constantes en la obra de Coomonte.

El rótulo con el nombre del Banco de España (fig. 8) ha perdido el simple carácter indicativo de esta entidad bancaria para transformarse en algo más, en una obra escultórica $(5,00 \times 4,00 \times 1,40 \mathrm{~m}$, aproximadamente). Se levanta sobre un pedestal de hormigón, advirtiéndose en el volumen de las letras, realizadas en hierro batido, galvanizado y posteriormente patinado, unas incisiones, cortes $y$, en ocasiones, aberturas, que permiten el paso de la luz para iluminar las distintas oquedades en un equilibrado juego volumétrico, aligerado por la presencia del vacío y de los contrastes lumínicos.

Si la obra de Coomonte en el Banco de España es, sin lugar a dudas, la de mayor envergadura en los últimos años, no por ello hay que olvidar otras aportaciones de este escultor, destacándose entre ellas las rejas de la Diputación Provincial de Zamora (1983) y la de la Caja de Ahorros de Zamora, en Toro (1986), realizadas en hierro forjado, material al que Coomonte sabe arrancar todas las posibilidades que encierra ${ }^{2}$.

En la primera de estas dos obras, las rejas de la Diputación Provincial de Zamora (fig. 9), el escultor respeta la estructura del edificio y su entorno sin renunciar a las experiencias preexistentes en el campo de la tradicional rejería castellana. Todo el conjunto, que consta de dos puertas $(2,85 \times 3,35 \mathrm{~m}$, y $4,70 \times 4,00 \mathrm{~m})$ y dieciocho rejas que recorren el perimetro del muro (cada una de ellas mide aproximadamente $1,70 \times 3,40$ $\mathrm{m})$, está integrado por elementos verticales, separados entre si unos doce o quince centímetros. Cada uno de estos elementos va acompanado por distintas formas decorativas en total armonia con el que le sigue, hasta dar lugar a dieciséis o veinte variantes en cuanto a motivos ornamentales se refiere. La totalidad de dichos elementos verticales se

2 La obra de este escultor se encuentra muy vinculada al trabajo del hierro, sirviendo como ejemplo el "Ostensorio" (1960) que mereció la Medalla de Oro de Escultura en la II Bienal de Arte Cristiano, celebrada en Salzburgo en 1960. En este sentido, véase: J. L. ALONSO COOMONTE, "Ostensorio", Arquitectura, Madrid, 1962, núm. 41, pág. 11-21; J. BONEU FARRE, obra citada, pág. 27-40. 
sujetan por dos llantas paralelas, aunque en el caso de las puertas, su verticalidad se rompe aproximadamente en el centro para crear un sistema de cerraduras de seguridad.

La reja de la Caja de Ahorros de Zamora $(3,20 \times 3,00 \mathrm{~m}$, aproximadamente), en Toro, cuyo boceto y cartón guarda esta entidad, presenta una estructura diametralmente opuesta a la anterior obra (figs. 10 y 11). Un irregular pero armonioso entramado de inspiración modernista recorre todo el espacio, representando una parra gigante con grandes racimos de uvas, que aluden a una de las principales riquezas de esta región. Tanto en esta obra como en la anterior se ponen de relieve, una vez más, las distintas soluciones que Coomonte puede introducir en el campo artístico de la rejería, campo, por otro lado, ampliamente tratado en su obra escultórica ${ }^{3}$.

Junto a estas últimas realizaciones de Coomonte, deben ser también destacados sus proyectos. Uno de ellos radica en la adquisición que, muy posiblemente, hará la Diputación Provincial de Zamora de en su obra titulada "El cerco de Zamora", para ser ubicada en los jardines de la parte posterior de dicha Diputación como simbolo del pasado histórico de la ciudad. La maqueta (figs. 12, 13 y 14), integrada por doce grupos escultóricos, data de los años 1975 y 1976, aproximadamente, y ha formado parte de una exposición dedicada a Coomonte en el Parador Nacional Condes de Alba de Aliste, de Zamora, celebrada entre los meses de julio y septiembre de 1988. En esta maqueta el escultor se aproxima a la idea que, posteriormente, desarrollará en bronce, en gran tamaño, y que está inspirada en el Poema del Cid, en sus diferentes personajes, simbolizados por coronas, escudos y yelmos -en cuyo interior se escribirá su historia- y que estarán situados sobre rocas naturales de grandes proporciones, procedentes, según la idea originaria, de Muelas del Pan (Zamora).

Un simbolismo figurativo alude a la personalidad de cada uno de los personajes, como el Cid Campeador, los reyes Sancho II y Alfonso VI, Doña Elvira, Doña Urraca... y las ciudades de Toro y Zamora, si bien se advierte una concepción más abstracta en la representación del desmembrado tronco de Bellido Dolfos. En los yelmos, coronas, cruces..., en ese conjunto de diferentes piezas escultóricas (figs. 15 y 16) que individualmente integran la maqueta, realizadas en hierro, se observa, junto a la agresividad de unos elementos puntiagudos, la valoración del volumen y

3 Véase: J. A. Ramirez, artículo citado, pág. 42 y 43. 
del vacío, de lo convexo y lo cóncavo, que permite el paso de la luz o, por el contrario, crea una zona de sombras, sin olvidar un cierto ingenuismo derivado de esas movidas y onduladas formas que se escapan de algunos yelmos, como queriendo evocar a los barbados personajes que representan. En ciertas piezas surge el movimiento al ser actuado un sencillo mecanismo, con lo que se introduce lo lúdico en la obra, una obra que en un futuro próximo será una realidad, tras adquirir su forma definitiva, como símbolo histórico de la ciudad de Zamora.

En la exposición anteriormente citada se recogían también otras muestras de la escultura de Coomonte, perteneciendo algunas de ellas ("Movimiento erogenético», "Encuentro", "Movimiento inquietante», "Fría mirada de la razón", "Héctor y Andrómaca", "Dólar, último ídolo") a la década de los años setenta, mientras que otras corresponden ya al período de la vida artística del escultor que se inicia tras su llegada a Zamora, objeto de este trabajo. Tal es el caso de una obra titulada «Homenaje a Castilla» $(1,10 \times 3,35 \times 1,25 \mathrm{~m})$ realizada en hierro pintado, en 1980 (fig. 18). Su concepción pone de manifiesto un juego de tensiones que tienden a la horizontalidad, modificada en parte por el desarrollo en el espacio de unas dinámicas formas curvilíneas que subrayan, a la vez que definen, la armónica estructura de esta obra.

Algo posterior, de 1981 concretamente, es "Desbloque" $(1,00 \times 1,62 \times 0,50 \mathrm{~m})$, pieza escultórica de hierro (fig. 17), en la que el espacio ha sido delimitado por una estructura formal, de vigorosa geometría y cerrada composición, como consecuencia del ordenamiento angular de unos elementos que confluyen en una forma circular, cuya esfericidad se rompe bruscamente para dar paso al espacio.

También de 1981 es otra realización de Coomonte, titulada «Castilla» $(0,80 \times 2,75 \times 0,90 \mathrm{~m})$, obra ejecutada en hierro, que pone de manifiesto la investigación en la geometría de unas formas abstractas, organizadas en el espacio a través de la dinámica de unos ritmos horizontales, que conducen a la interacción del espacio y la materia y, consecuentemente, a la plasticidad de ambos.

Con simultaneidad a su quehacer en el terreno escultórico, la actividad de Coomonte se centra también en el campo del diseño y en el de la docencia. Según palabras del escultor, el diseño constituye "un mundo amable, como un dormir en un sueño bonito", que le permite crear unas formas inspiradas en los tiempos perdidos del romanticismo, en el Art nouveau y en el Art déco. Al mismo tiempo, siente la necesidad de "salvar el objeto, lo entrañable" que hay en los diversos y, a la vez, curiosos objetos que encuentra: aparatos de radio, discos, postales románticas, 
máquinas de coser, rejas antiguas e, incluso, las pulseras de los carros de Castilla.... limitándose en unas ocasiones a restaurarlos, aunque en otras, los transforma hasta convertirlos en mesas, lámparas..., puesto que cada uno de dichos objetos tiene una función estética y social que cumplir, destinada a aquellas personas que todavia vibran ante el pasado.

Son muy variadas las realizaciones de Coomonte dentro de este campo, destacándose entre ellas unas pequeñas esculturas, a las que califica de "piezas domésticas" por encontrar en la casa su entorno adecuado, que datan de 1988. Una de ellas (fig. 19), titulada "Pliegues" $(0,20 \times 0,11 \times 0,10 \mathrm{~m}$, aproximadamente), está ejecutada en poliéster sin fibra de vidrio, material que ha sido sometido a una determinada temperatura hasta poder ser manipulado con unos guantes de amianto. A partir de este momento se pone en juego la habilidad, maestría, espontaneidad y capacidad de improvisación del escultor, que en un corto espacio de tiempo - unos quince o veinte minutos - ha de arrugar la materia antes de que se enfrie hasta transformarla, en este caso, en una abstracción formal en la que se ha buscado el dinamismo y los efectos de claroscuro provocados por los ritmos sinuoso de unas formas curvilíneas, muy fluidas y de gran plasticidad.

Del mismo año y material son otras pequeñas esculturas, denominadas "Seseras" (fig. 20), en las que también se aprecia un marcado predominio de lo curvilíneo, aunque a través de la obsesiva repetición de unos motivos ondulantes que se entrelazan hasta confundirse unos con otros, para terminar conformando unos cerrados volúmenes de compacta estructura.

La transparencia del vidrio desempeña un papel muy importante en una escultura $(1,50 \times 0,40 \times 0,40 \mathrm{~m})$ realizada en este material, en 1988 . Esta obra, dotada de un carácter totémico, se inicia en su base con una forma hexagonal que, paulatinamente, tras reducir su diámetro, casi se transforma en cilíndrica. El sólido volumen de esta pieza, de irregulares y abultadas superficies, alberga un foco luminoso que, al ser activado, se proyecta desde el interior originando unos efectos lumínicos enriquecidos por las diferentes variaciones cromáticas del vidrio.

Este mismo material también ha sido empleado por Coomonte en la realización de distintos objetos, entre ellos una mesa integrada por unos elementos vegetales, desarrollados a partir de una forma cúbica de la que se desprenden unas flores de vidrio de color y hierro, que se transparentan a través del grueso cristal cuadrangular dispuesto a modo de tablero. 
Además de estas realizaciones, podrían citarse otras que son claros exponentes de la actividad de Coomonte en el campo del diseño, actividad que junto a la escultórica compagina, como ya se dijo antes, con la docente. En este sentido, desde el curso 1986-1987 es profesor de Procedimientos de Escultura y Pintura en la Facultad de Bellas Artes de Salamanca, materia orientada con gran libertad para así encauzar a sus alumnos dentro del difícil mundo del arte.

Escultura, diseño, docencia..., y, sin embargo, Coomonte considera que todo ello no es suficiente. Va en la búsqueda de algo más, siente que ha de seguir investigando, explicar su angustia... Desde su estudio de San Marcial, una casa de labranza transformada en cómoda y bonita vivienda, rodeada de una vegetación que antes no existía y que ahora se confunde con la arquitectura, desde ese lugar de paz y tranquilidad, Coomonte piensa, equivocadamente, que su obra es inútil, que no sirve socialmente, que a nadie le interesa y, por lo tanto, siente la necesidad de manifestar a la sociedad que no está en su sitio todavia.

En su preocupación por Castilla, por la problemática de esta región y su futuro, se vuelve hacia el pasado, en un deseo de querer salvarla en la medida en la que recupera los más variados útiles de labranza, convertidos ya en material de desecho y casi en testimonio arqueológico, para iniciar con ellos, como en una especie de "collage", la obra de lo que Coomonte considera su última etapa. En su estudio se amontonan arados, ruedas, trillos, asientos de maquinaria antigua, vigas de lagar..., y los yugos. Se siente especialmente atraído por el yugo, por su forma, muy escultórica, a la que ha querido acercarse en alguna de sus obras con el deseo de investigar en su contenido, de captar todas las posibilidades que encierra.

Como símbolo de esa tierra castellana, como referencia al entorno en el que se encuentra por evocar los pliegues de la corteza del terreno, se recorta sobre el espacio, en el exterior del estudio, una vigorosa pieza $(2,80 \times 2,50 \times 0,40 \mathrm{~m}$, aproximadamente $)$ de hierro forjado, de unos doce milimetros de espesor, en la que actualmente está trabajando (fig. 21). Coomonte, tras haber plegado el material por tensión en la fragua, lo ha dejado a la intemperie con objeto de someterlo a un tratamiento de óxido natural para, posteriormente, paralizar ese color y proceder a su acabado. Una vez más, el escultor deja constancia de su preferencia por los grandes formatos, por la monumentalidad o la tendencia a ella, ya que es en el campo del diseño, como anteriormente se ha visto, donde Coomonte empequeñece el tamaño de la obra para convertirla en un objeto fácil, asequible. Estas grandes piezas constituyen una costosa experiencia para él, dada la dificultad que entraña su ejecución hasta conseguir, 
como en el caso de esta obra, curvar el material para lograr una serie de inflexiones que permiten el juego de lo cóncavo y lo convexo junto con el consiguiente contraste lumínico que, unido todo ello a la tonalidad que adquiere el hierro tras el proceso de oxidación, supone el reflejo de esa tierra castellana, áspera, seca, desértica, y, sin embargo, bella.

Castilla es, pues, el futuro de Coomonte, el punto de partida de lo que él considera su última etapa, pero que en realidad será una nueva, en la espera de otras más, dentro de la evolución artística de este escultor. 


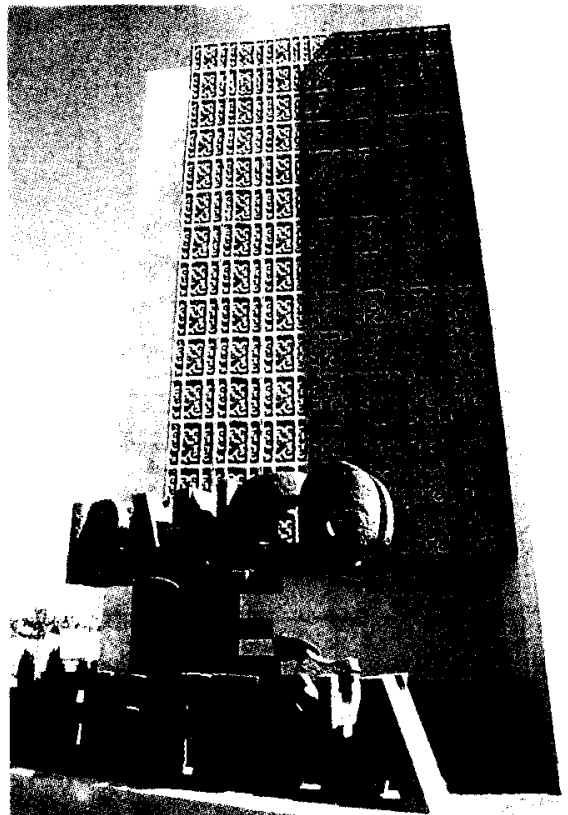

Fig. 1. Banco de Espana. Zamora.

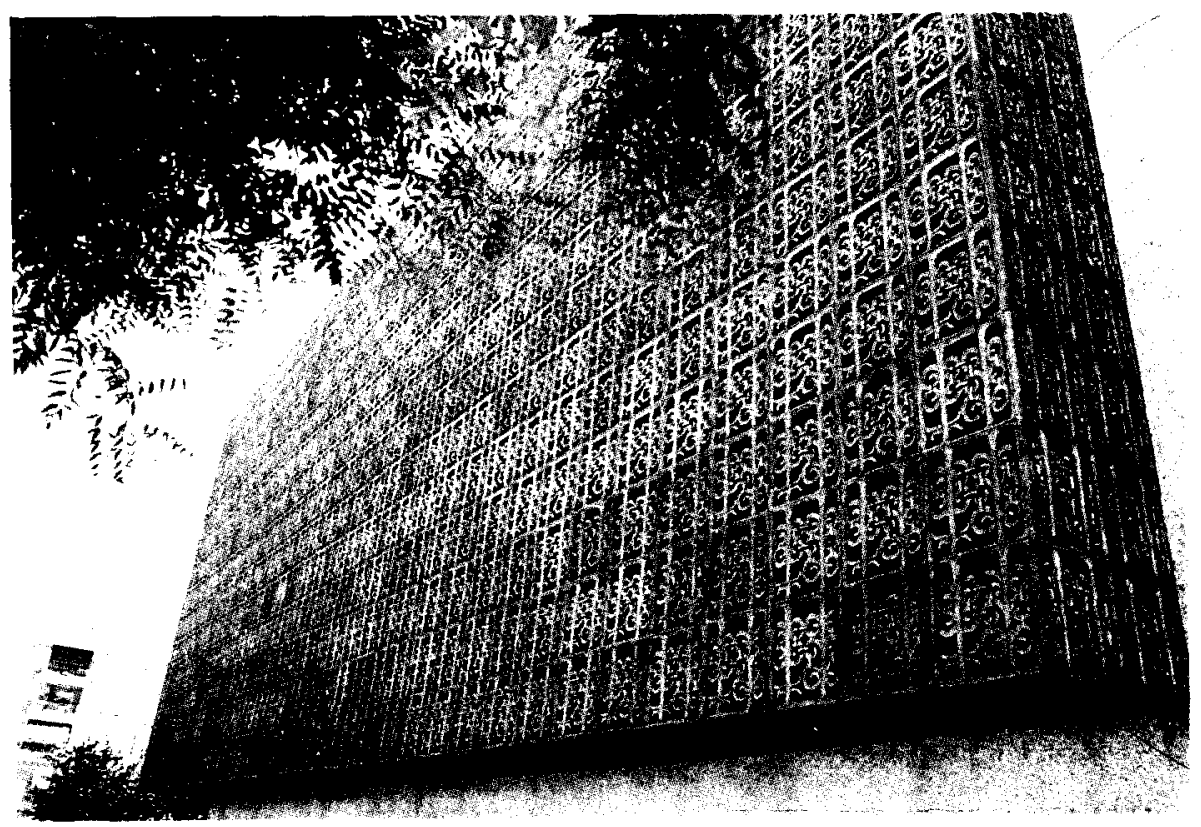

Fig. 2. Banco de España. Zamora. Celosia. 


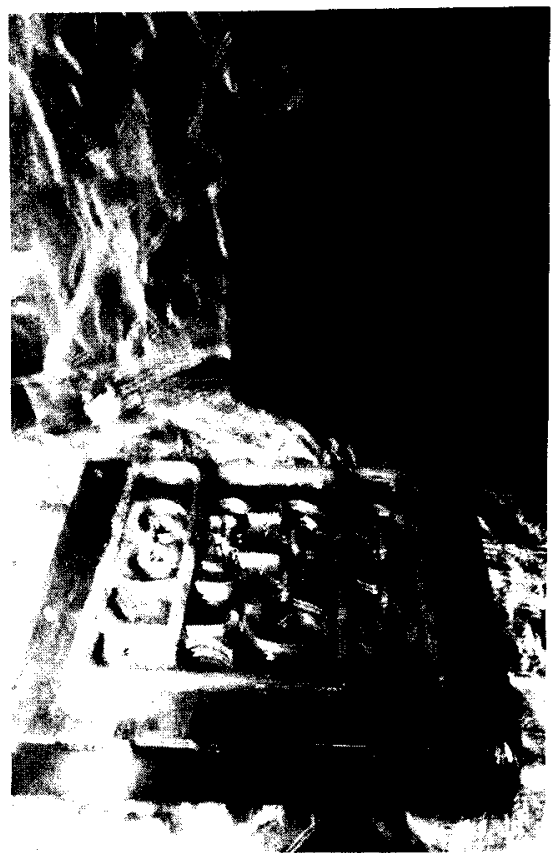

Fig. 3. Banco de España. Zamora. Coquilla.

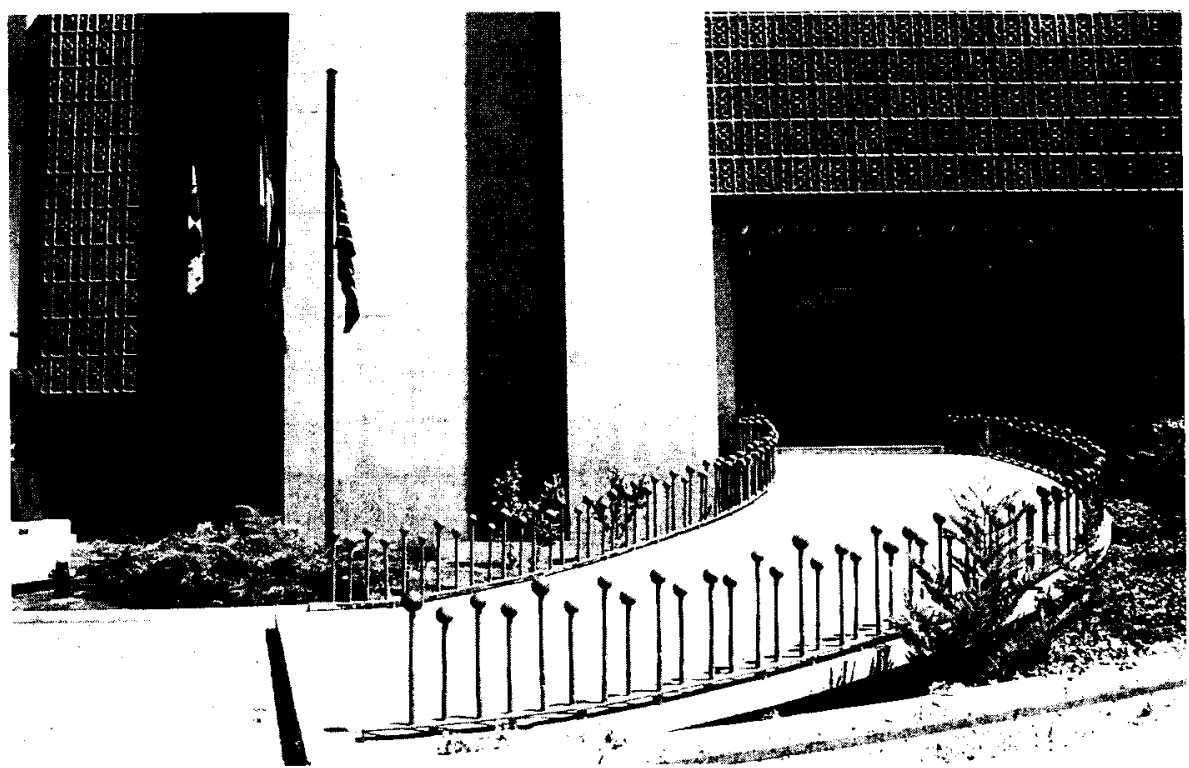

Fig. 5. Banco de España. Zamora. Puerta principal. 
Coomonte, hoy

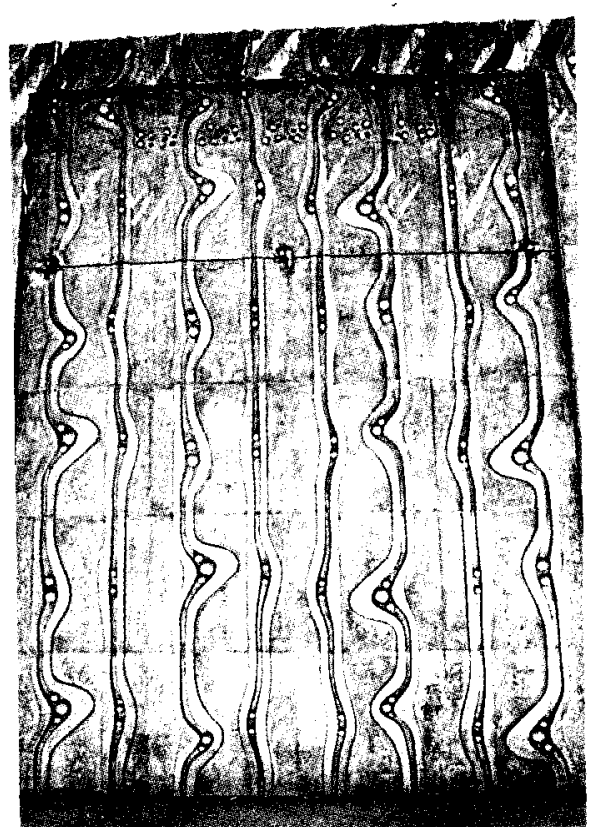

Fig. 6. Banco de España. Zamora. Puerta.

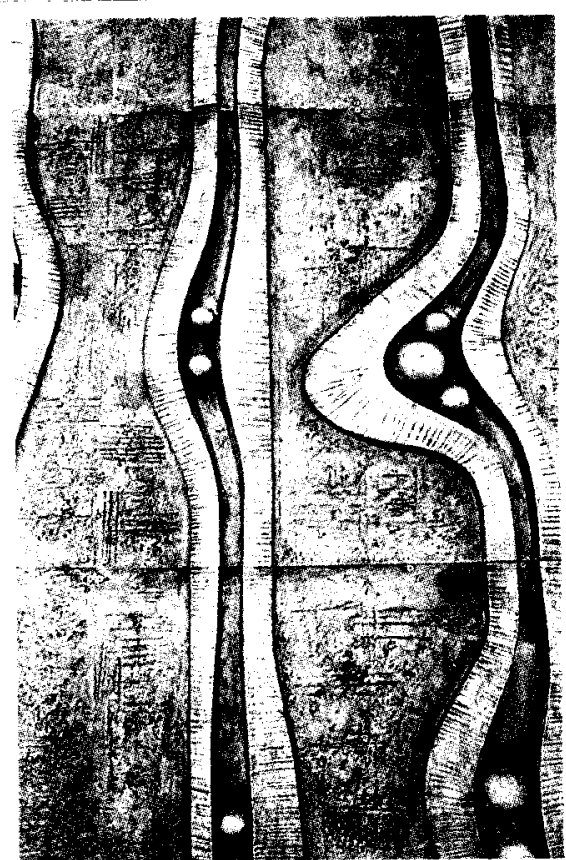

Fig. 7. Banco de España. Zamora. Detalle de una de las puertas.

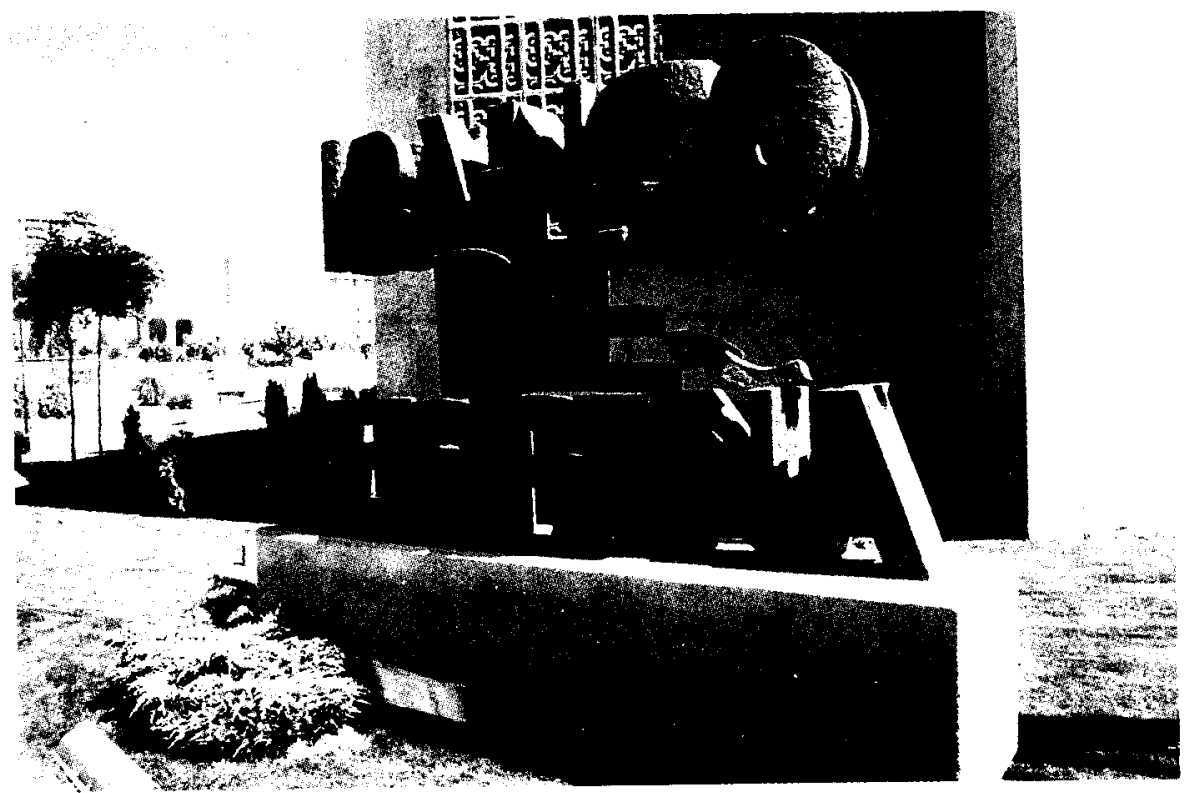

Fig. 8. Banco de España. Zamora. Rotulo. 


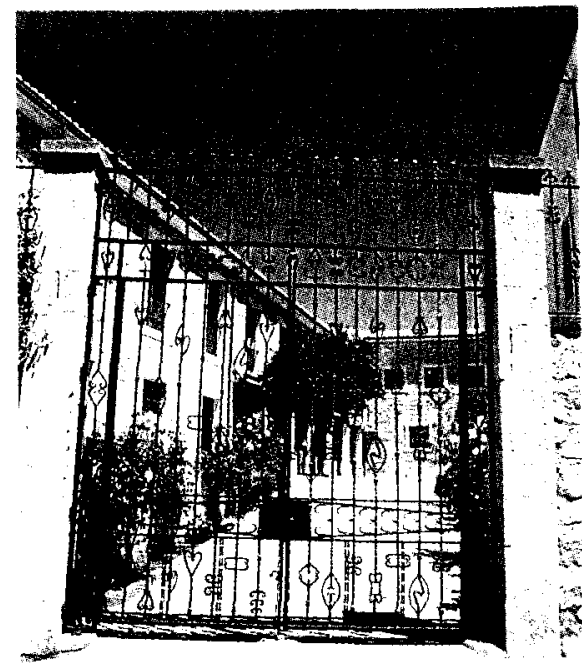

Fig. 9. Diputacion Provincial de Zamora. Reja.

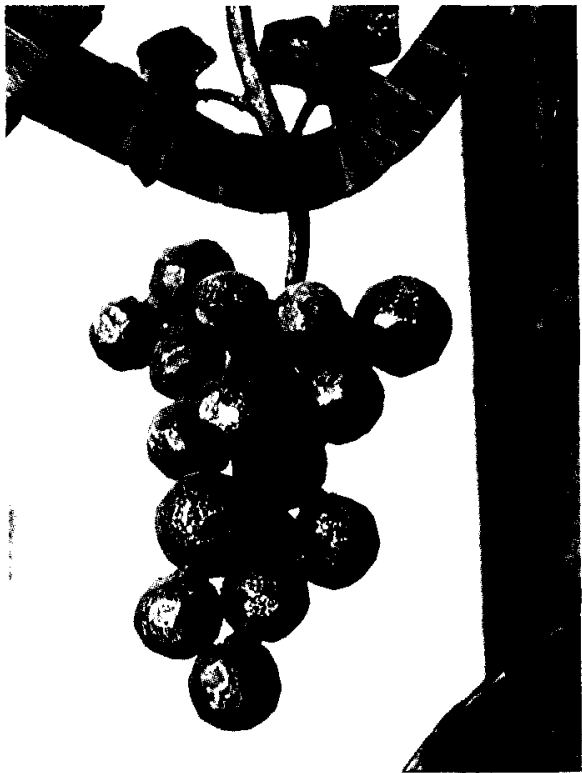

Figs. 10. Caja de Ahorros de Zamora, Toro. Detalle de la reja.

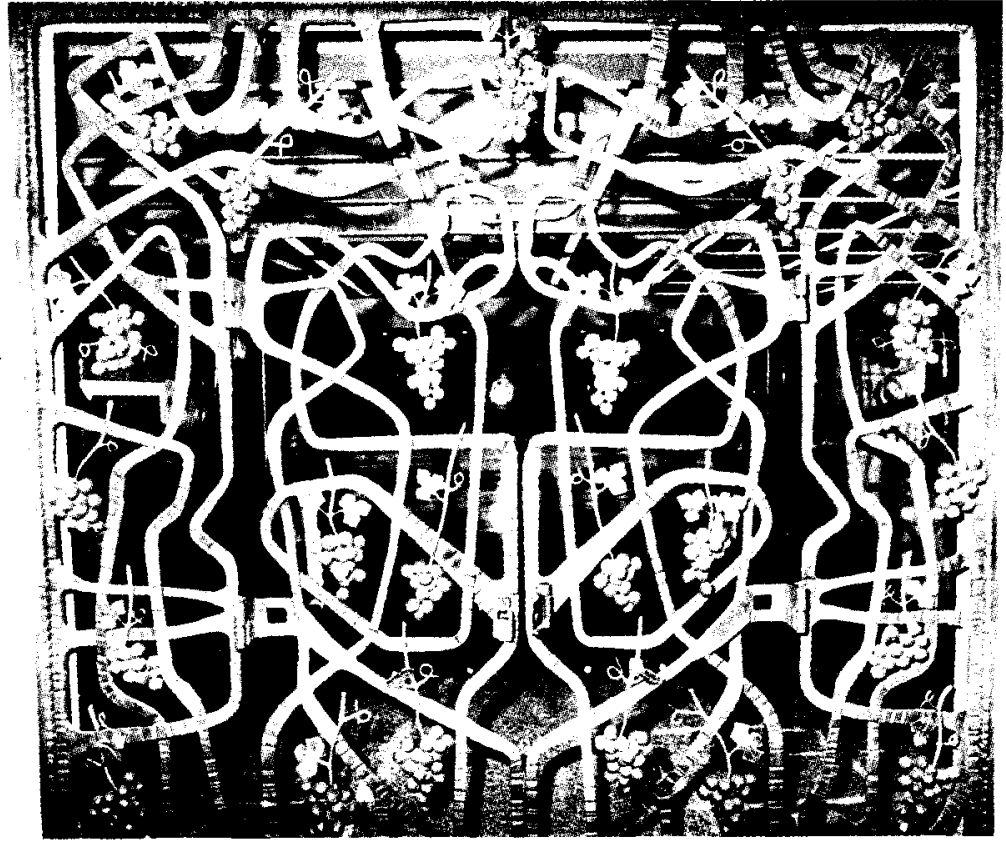

Figs. 11. Caja de Ahorros de Zamora, Toro. Reja. 

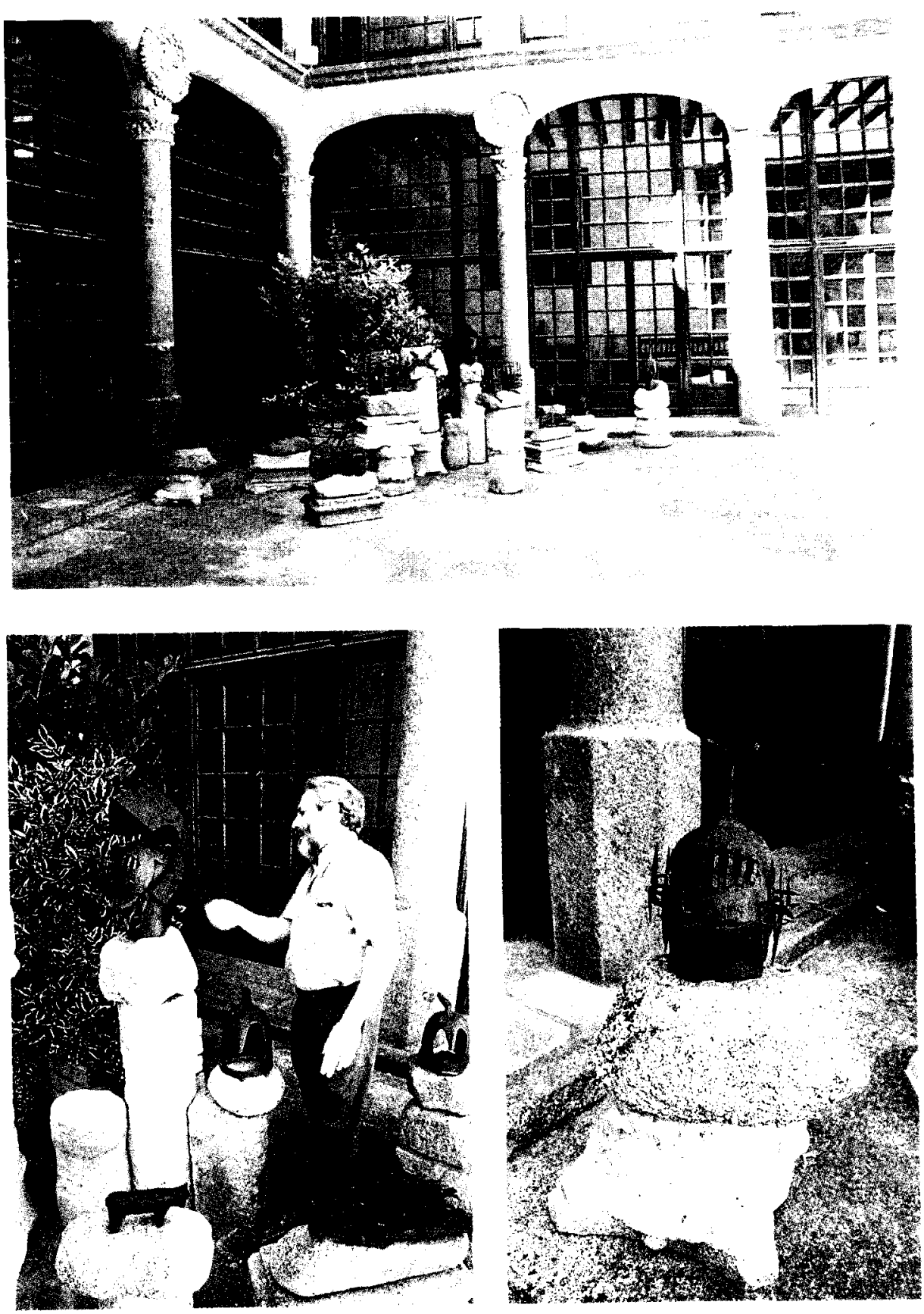

Figs. 12,13 y 14. El Cerco de Zamora. Detalles. 


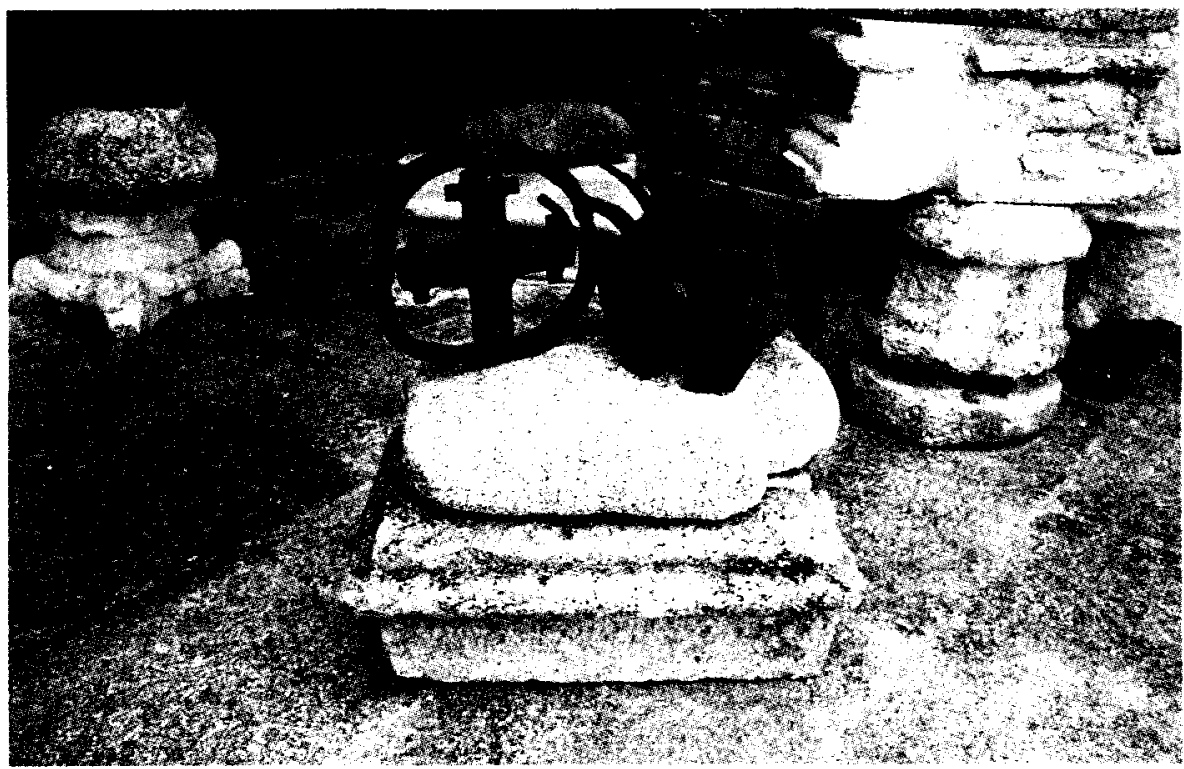

Figs. 15. El Cerco de Zamora. Detalle.

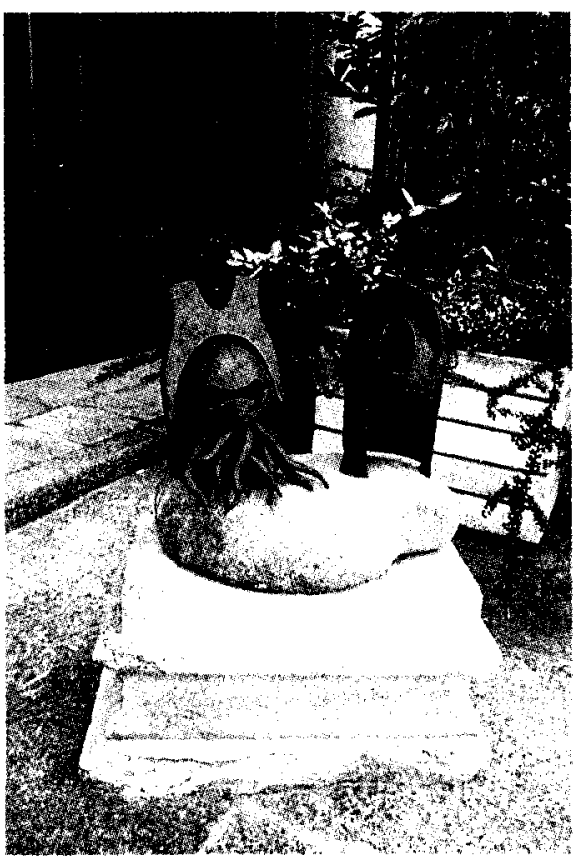

Figs. 16. El Cerco de Zamora. Detalle.

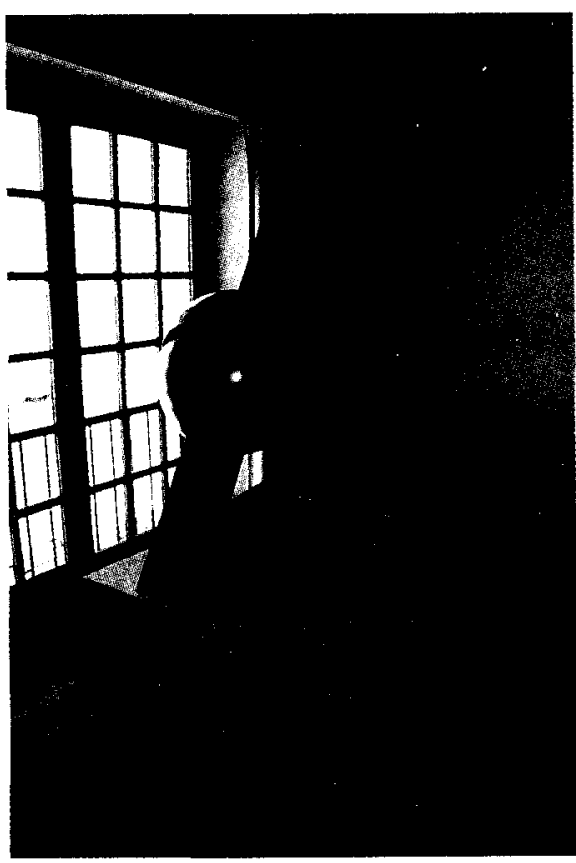

Fig. 17. Desbloque. 


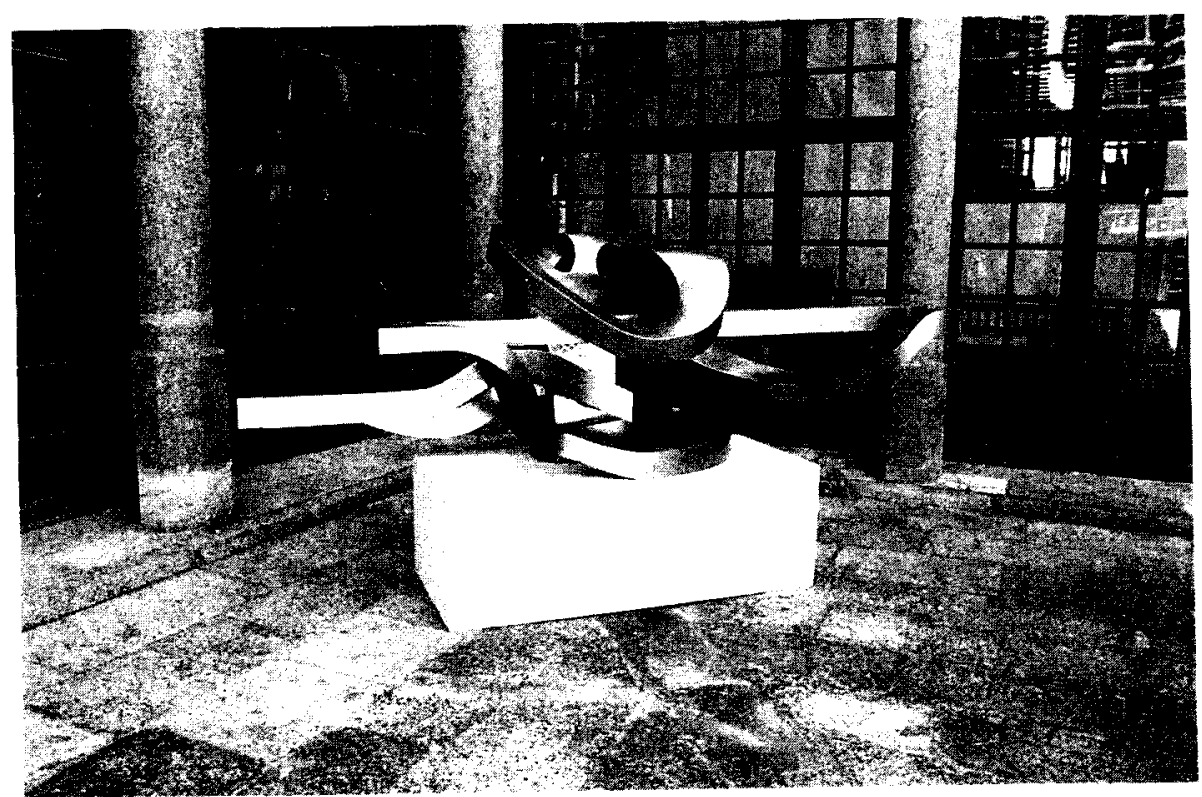

Fig. 18. Homenaje a Castilla.

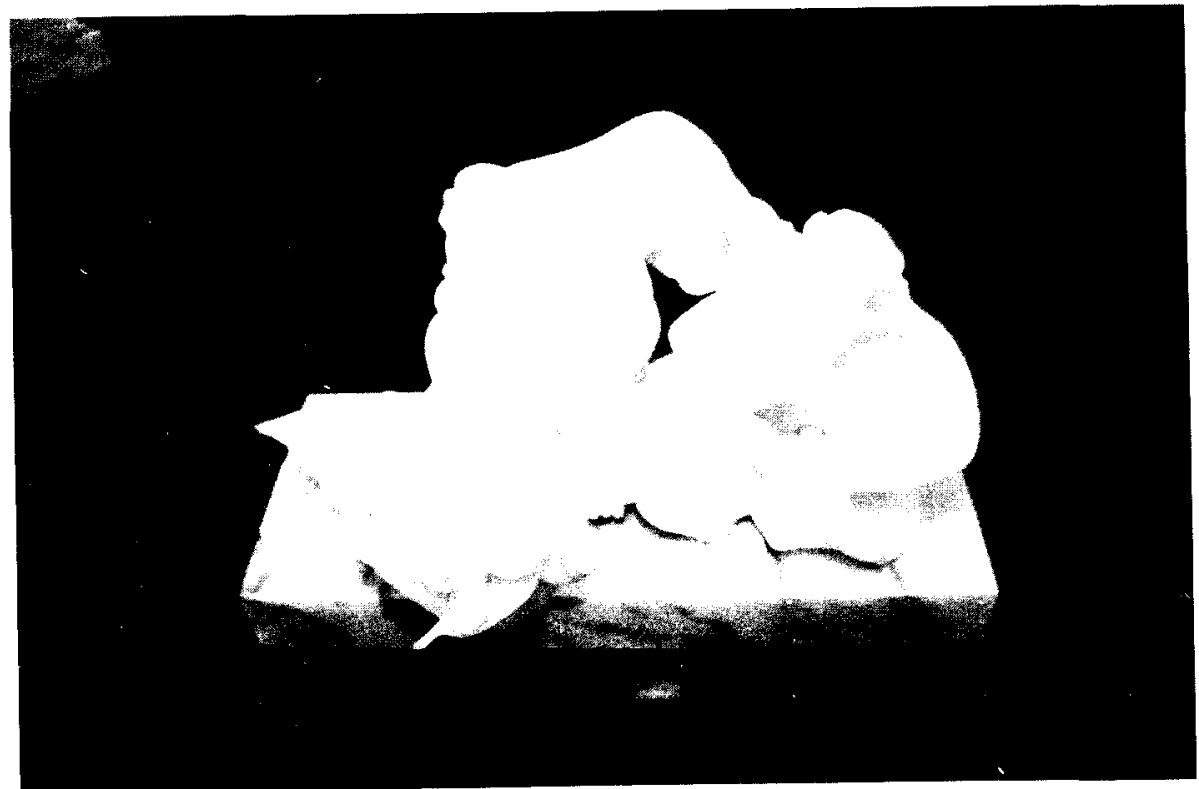

Fig. 19. Pliegues. 


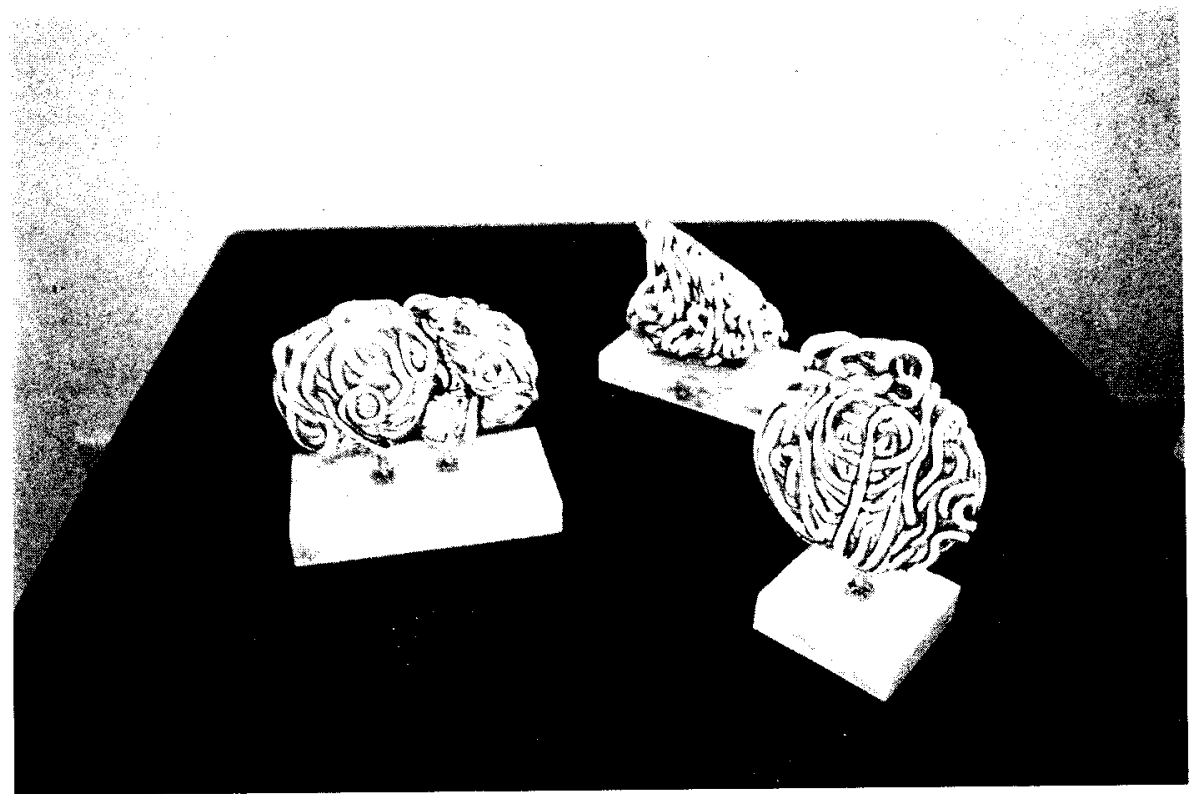

Fig. 20. Seseras.

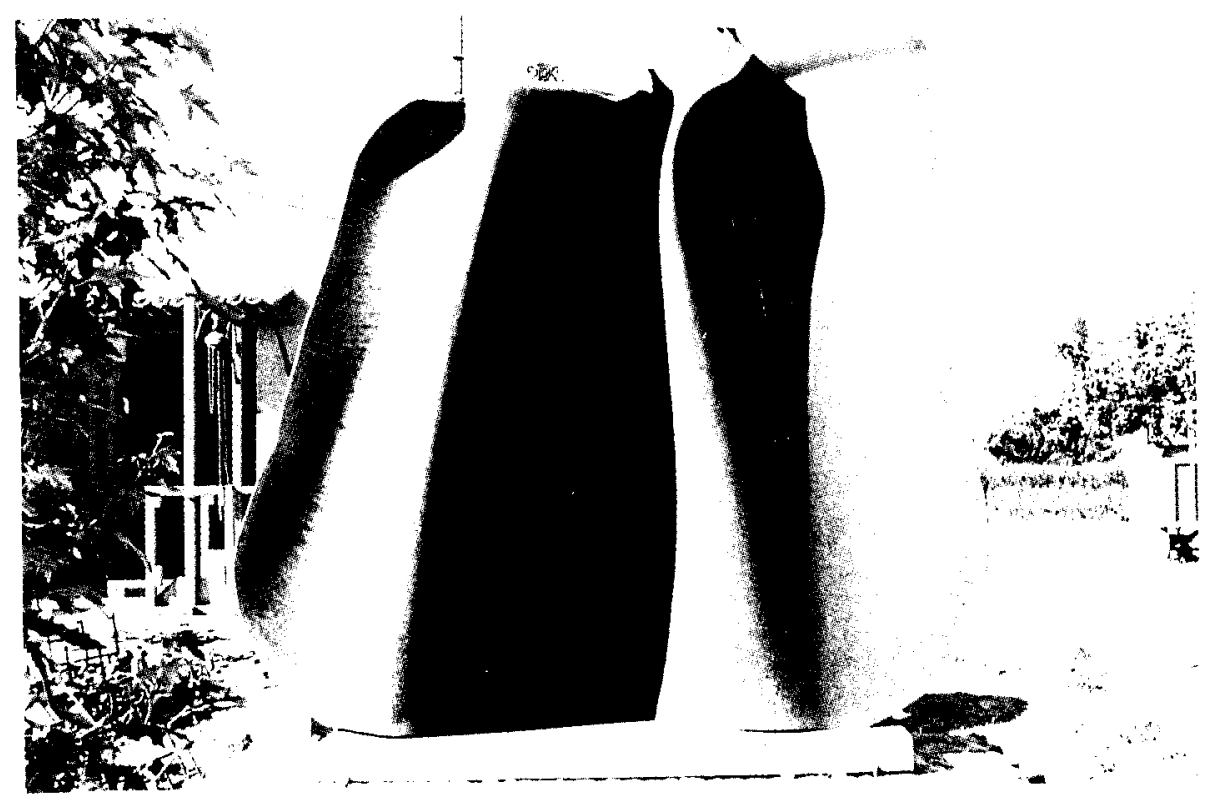

Fig. 21. Escultura en realización. 